\title{
Metal-dependent gene regulation in the causative agent of Lyme disease
}

\author{
Bryan Troxell ${ }^{*}$ and X. Frank Yang \\ Department of Immunology and Microbiology, Indiana University School of Medicine, Indianapolis, IN, USA
}

Edited by:

Frédéric J. Veyrier, Institut Pasteur,

France

Reviewed by:

Jon Skare, Texas A\&M Health

Science Center, USA

Val Culotta, Johns Hopkins

University, USA

*Correspondence:

Bryan Troxell, Prestage Department

of Poultry Science, North Carolina

State University, 334E Scott Hall,

Campus Box 7608, Raleigh,

NC 27695-7608, USA

e-mail: bryan_troxell@ncsu.edu

${ }^{\dagger}$ Present address:

Bryan Troxell, Prestage Department

of Poultry Science, North Carolina

State University, Raleigh, USA
Borrelia burgdorferi $(B b)$ is the causative agent of Lyme disease transmitted to humans by ticks of the Ixodes spp. $B b$ is a unique bacterial pathogen because it does not require iron $\left(\mathrm{Fe}^{2+}\right)$ for its metabolism. Bb encodes a ferritin-like Dps homolog called NapA (also called BicA), which can bind Fe or copper $\left(\mathrm{Cu}^{2+}\right)$, and a manganese $\left(\mathrm{Mn}^{2+}\right)$ transport protein, Borrelia metal transporter $\mathrm{A}(\mathrm{BmtA})$; both proteins are required for colonization of the tick vector, but BmtA is also required for the murine host. This demonstrates that $B b$ 's metal homeostasis is a critical facet of the complex enzootic life cycle between the arthropod and murine hosts. Although metals are known to influence the expression of virulence determinants during infection, it is unknown how or if metals regulate virulence in $B b$. Recent evidence demonstrates that $B b$ modulates the intracellular $\mathrm{Mn}^{2+}$ and zinc $\left(\mathrm{Zn}^{2+}\right)$ content and, in turn, these metals regulate gene expression through influencing the Ferric Uptake Regulator (Fur) homolog Borrelia Oxidative Stress Regulator (BosR). This mini-review focuses on the burgeoning study of metal-dependent gene regulation within $B b$.

Keywords: Borrelia burgdorferi, Lyme disease, copper, manganese, zinc, calprotectin

\section{INTRODUCTION}

Borrelia burgdorferi $(B b)$ is the causative agent of a multisystem disorder known as Lyme disease. $B b$ persists within an enzootic cycle that includes two diverse hosts, a tick vector and a warm-blooded host, typically small rodents. "Hard ticks" of the Ixodes genus are important arthropod hosts for colonization by $B b$. Ixodes ticks are slow-feeding ticks $(\approx 48 \mathrm{~h}$ for a bloodmeal) that have a 2-year life cycle including three distinct stages: larvae, nymph, and adult (Figure 1). At each stage, ticks will feed once on a warm-blooded host then undergo a molting process, which precedes a period of dormancy that may last months (Figure 1). Because $B b$ colonization of ticks does not appear to occur through transovarial transmittance, unfed larvae ticks are naïve and acquire $B b$ during feeding on an infected warmblooded host. Feeding ticks can acquire $B b$ at any stage of the usual 2-year life cycle and transmission of $B b$ can occur during feeding on an animal host at any subsequent stage of the life cycle. Small rodents (especially the white-footed mouse, Peromyscus leucopus) are the primary animal reservoirs for $B b$ within this enzootic cycle and are sources for the bloodmeal during the larval and nymphal stages (Figure 1). Unlike most bacterial pathogens, $B b$ lacks lipopolysaccharide (LPS), lipooligosaccharide (LOS), and capsule (Radolf and Samuels, 2010). Bb is highly motile due to the presence of flagella; however, $B b$ 's flagella are contained within the periplasmic space between the outer and inner membranes. Therefore, $B b$ 's flagella is not surface exposed and is called an endoflagella. The endoflagella are anchored at each end of the cell and provide $B b$ with a characteristic corkscrew movement. Despite $B b$ 's limited metabolism and fastidious nature $B b$ survives within two hosts, a tick vector and a small rodent host. Other animals, such as humans, are infected by $B b$, but are not considered important for persistence of $B b$ within the enzootic cycle. Of significant interest, $B b$ is one of the few pathogens that does not require iron $\left(\mathrm{Fe}^{2+}\right)$ to grow (Posey and Gherardini, 2000). Given the importance of $\mathrm{Fe}^{2+}$ in the regulation of virulence within other bacteria, it is not clear which metals $B b$ utilize for regulating virulence factors. Recent work suggests that metals may play an important role in regulation of virulence within $B b$.

Metal homeostasis is important to maintain the metabolism of bacterial pathogens. This is accomplished through the combined action of metal transporters, both importers and exporters, which control the abundance of specific metals and the ratio of the transition metals within the cell. Although some metal transporters are highly specific for a cognate metal, others are capable of importing several metals with different affinity of each metal. In addition to the importance of metals in bacterial physiology, metals play a critical role in the control of gene regulation within pathogens. The role of metals within $B b$ is not fully understood. Only a single protein, Borrelia metal transporter A (BmtA) is known to participate in metal transport. Analysis of the intracellular metal content with in vitro grown $B b$ suggests that $\mathrm{BmtA}$ transports $\mathrm{Mn}^{2+}$ since this metal is nearly undetectable in $\Delta b m t A$ strains (Ouyang et al., 2009a; Troxell et al., 2013). BmtA may also be involved in the import/export of other metals since deletion of $b m t A$ alters the intracellular concentrations of $\mathrm{Fe}^{2+}, \mathrm{Cu}^{2+}$, and $\mathrm{Zn}^{2+}$ (Wang et al., 2012). The mechanism of BmtA-dependent metal transport is still unknown, but recent evidence indicates that $\mathrm{BmtA}$ and $\mathrm{Mn}^{2+}$ are involved in regulation of virulence through a Ferric uptake regulator (Fur) homolog named Borrelia Oxidative Stress Regulator (BosR). BosR is redox sensing DNA binding protein that utilizes $\mathrm{Zn}^{2+}$ as a cofactor (Boylan et al., 2003; Katona et al., 2004). Discussed here is the role of metals in 


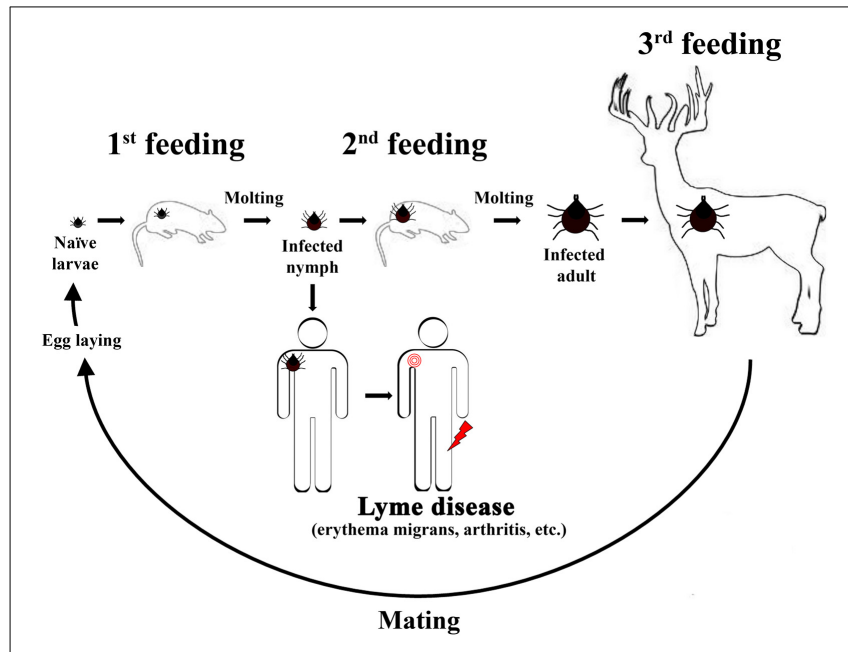

FIGURE 1 | The usual 2-year enzootic cycle of the Lyme disease spirochete. A naïve Ixodes scapularis larvae will feed on a small rodent near the end of the Summer season or early Fall. The feeding larvae can acquire $B b$ at this feeding (1st feeding) and remain colonized throughout the molting process, which occurs during the Winter season. For the 2nd feeding, infected nymphs will feed late in the Spring season or early in the Summer season. The infected nymphs transmit $B b$ to either a small rodent host, which maintains the enzootic cycle in nature, or humans (accidental host). Infected humans develop Lyme disease and may develop erythema migrans (signified by a red bulls eye near the shoulder in the figure shown) shortly after an infected nymph feeds. Typically, if subject to late Lyme manifestations Lyme disease patients develop Lyme arthritis at one or both knee joints (signified by a red lightning bolt near the knee in the figure shown). For the final feeding (3rd feeding), nymphs will molt and emerge as adults to feed on large mammals, such as deer, during the Fall season. Deer are considered incompetent hosts for $B b$, but the 3rd feeding is important in the enzootic cycle because female ticks will mate and lay eggs over the Winter season. Naïve larvae will emerge following hatching and the cycle begins anew.

$B b$ physiology and gene expression as it relates to virulence factors required in vivo.

\section{Bb: A NON-COMBATANT IN THE WAR FOR Fe ${ }^{2+}$}

Just as a siege limits the influx of food and supplies to an enemy's stronghold, during infection the host transports metals away from the locale of pathogens and synthesizes copious amounts of metal-chelating proteins to limit access of these essential micronutrients. The hosts' ability to produce metal-chelating proteins is important for defending against pathogens since deletion of the chelating protein calprotectin enhances virulence of Acinetobacter baumannii, Staphylococcus aureus, and the opportunistic yeast pathogen Candida albicans (Corbin et al., 2008; Kehl-Fie et al., 2011; Damo et al., 2013). Calprotectin can bind $\mathrm{Mn}^{2+}$ and $\mathrm{Zn}^{2+}$ and is an abundant protein present in neutrophils (Yui et al., 2003), which are an early host defender against invading pathogens. Some bacterial pathogens are capable of overcoming the growth inhibition exerted by calprotectin; Salmonella enterica serovar Typhimurium (S. Typhimurium) expresses a high affinity $\mathrm{Zn}^{2+}$ ATP-binding cassette (ABC) transport system that outcompetes $\mathrm{Zn}^{2+}$ chelation by calprotectin (Liu et al., 2012). Calprotectin is known to inhibit in vitro growth of $B b$ through $\mathrm{Zn}^{2+}$ sequestration (Lusitani et al., 2003).
The contribution of calprotectin to $B b$ growth in vivo is unknown, but $B b$ encodes several putative uncharacterized $\mathrm{ABC}$ transporters that could be involved in metal transport during infection. In addition, whether calprotectin inhibits $B b$ growth through $\mathrm{Mn}^{2+}$ chelation is unknown. The fierce war between the pathogen and host for accessibility of $\mathrm{Fe}^{2+}$ poses a problem to pathogens; however, $B b$ has evolved a novel solution by becoming a noncombatant in the war for $\mathrm{Fe}^{2+} . \mathrm{Bb}$ does not appear to transport $\mathrm{Fe}^{2+}$, lacks many biosynthetic and catabolic pathways that require $\mathrm{Fe}^{2+}$, and exhibits no defect in growth in the absence of detectable $\mathrm{Fe}^{2+}$ (Posey and Gherardini, 2000). Although a recent study indicates there is detectable $\mathrm{Fe}^{2+}$ within $\mathrm{Bb}$, the physiological relevance of this finding remains uncertain (Wang et al., 2012). Another study did not detect intracellular $\mathrm{Fe}^{2+}$ following in vitro cultivation of $B b$ (Aguirre et al., 2013). Therefore, additional experiments are required to address these discrepancies. At this point, how $\mathrm{Fe}^{2+}$ is transported within $\mathrm{Bb}$ is unknown. Future work is required to determine the contribution of intracellular $\mathrm{Fe}^{2+}$ to $B b$ gene regulation and metabolism. Instead, because calprotectin inhibits $B b$ growth by $\mathrm{Zn}^{2+}$ sequestration, the existing data suggests that $\mathrm{Zn}^{2+}$ is an important metal within the metabolism of $B b$. This is supported by the $\mathrm{Zn}^{2+}$. dependent enzymatic activity of peptide deformylase (Nguyen et al., 2007) and the glycolytic enzyme fructose-1,6-bisphosphate aldolase (Bourret et al., 2011). Furthermore, peptide deformylase may be an essential enzyme (Jain et al., 2005) and, since glycolysis is the sole mechanism for the generation of ATP within $B b, \mathrm{Zn}^{2+}$ may be a critical metal for $B b$.

\section{BicA AND BmtA: TWO PROTEINS WITH NOVEL FUNCTION WITHIN Bb}

Bacteria encode metal binding proteins (ferritins or ferritinlike proteins) that store metals and serve as a facile source of essential metals when encountering a metal-depleted environment. $B b$ encodes a metal binding protein (NapA or BicA) that exhibits homology to the ferritin-like Dps present in other bacteria. Purified BicA is capable of binding $\mathrm{Fe}^{2+}$ or $\mathrm{Cu}^{2+}$, but lacks either metal when isolated (Li et al., 2007; Wang et al., 2012). The majority of studies have focused on the role of $\mathrm{Fe}^{2+}$ chelation by the host in nutritional immunity, but recent evidence demonstrates the importance of chelating $\mathrm{Zn}^{2+}$ and $\mathrm{Mn}^{2+}$ in thwarting bacterial infections (Kehl-Fie and Skaar, 2010). However, as part of the antimicrobial defense present within ticks, an antimicrobial peptide, known as microplusin, inhibits bacterial growth by $\mathrm{Cu}^{2+}$ chelation (Silva et al., 2009, 2011). Microplusin is expressed within the hemocele of ticks (Esteves et al., 2009), implying that this locale is a $\mathrm{Cu}^{2+}$ limited environment. $\mathrm{Bb}$ does appear to regulate its intracellular $\mathrm{Cu}^{2+}$, but the relevance or need for $\mathrm{Cu}^{2+}$ is unknown (Wang et al., 2012). The importance of BicA to the enzootic cycle is restricted to residence within the tick vector ( $\mathrm{Li}$ et al., 2007), implying that $\mathrm{Zn}^{2+}$ and $\mathrm{Cu}^{2+}$ are limiting within this host.

The role of $\mathrm{Mn}^{2+}$ in $B b$ metabolism is not understood. The gene $b m t A$, encoding a $\mathrm{Mn}^{2+}$ transport protein $\mathrm{BmtA}$, is not essential for in vitro growth within virulent $B b$ strains from the B31 (tick isolated) and 297 (human isolated) lineages despite reducing cellular $\mathrm{Mn}^{2+}$ to near undetectable concentrations 
(Ouyang et al., 2009a; Troxell et al., 2013). Bb cultivation in vitro requires a complex growth medium called BSK (Barbour, 1984). Treatment of BSK medium with a chelating resin, called Chelex, results in significant changes of the concentrations of metals. Chelex treatment of BSK reduces $\mathrm{Zn}^{2+}$, but $\mathrm{Mn}^{2+}$ becomes undetectable in the medium. Despite the undetectable $\mathrm{Mn}^{2+}$ in Chelex-treated BSK growth medium, no growth defects are observed for wild-type or $\Delta b m t A$ strains during cultivation in this medium (Troxell et al., 2013). BmtA has homology to the GufA family of metal transporters (Guerinot, 2000). BmtA has 8 membrane spanning domains and is predicted to transport cations through a novel mechanism (Ouyang et al., 2009a). To date, only a single protein within $B b$ is characterized as being $\mathrm{Mn}^{2+}$-dependent; specifically, the superoxide dismutase (SOD) encoded by $\operatorname{sodA}$ (Troxell et al., 2012; Aguirre et al., 2013). The expression of $b m t A$ and the intracellular concentration of $\mathrm{Mn}^{2+}$ are enhanced during cultivation at $25^{\circ} \mathrm{C}$, suggesting there may be a requirement for $\mathrm{Mn}^{2+}$ at cooler temperatures (Ojaimi et al., 2003; Troxell et al., 2013). The physiological need for more $\mathrm{Mn}^{2+}$ at $25^{\circ} \mathrm{C}$ is unknown, but this may be due to the need for defense against reactive oxygen species (ROS) because $B b$ encodes a Mn-dependent SOD and lower temperatures contain increased concentrations of dissolved $\mathrm{O}_{2}$ that could lead to enhanced formation of superoxide radical $\left(\mathrm{O}_{2}^{-}\right)$(Troxell et al., 2012; Aguirre et al., 2013). However, $B b$ may encode additional proteins that require $\mathrm{Mn}^{2+}$.

$\mathrm{Mn}^{2+}$ is considered an essential trace element within biology. In bacteria, $\mathrm{Mn}^{2+}$ is critical for defense against several stresses such as oxidative stress, bile stress, and resistance to antibiotics (Anjem et al., 2009; Srinivasan et al., 2012). In addition, $\mathrm{Mn}^{2+}$ is involved in gene regulation through indirect mechanisms. For instance, the alarmone guanosine tetraphosphate (ppGpp) is synthesized and degraded by SpoT/RelA homolog proteins. During conditions of nutrient deprivation, ppGpp is synthesized and binds to the RNA polymerase (RNAP) in order to enhance transcription of genes important for survival or virulence while reducing transcription of genes involved in growth and cell division (Magnusson et al., 2005). SpoT/RelA homologs contain a highly conserved $\mathrm{Mn}^{2+}$ binding site and require $\mathrm{Mn}^{2+}$ as a cofactor for the enzymatic degradation of ppGpp (Sy, 1977; Sun et al., 2010). Bb encodes a SpoT/RelA homolog, bb0198, that is induced during serum starvation and is responsible for both synthesis and degradation of ppGpp (Concepcion and Nelson, 2003; Bugrysheva et al., 2005). This suggests that $B b$ may require $\mathrm{Mn}^{2+}$ in order to initiate cell growth. Recently, $B b$ 's peptide deformylase was isolated with bound $\mathrm{Mn}^{2+}$ (Aguirre et al., 2013); however, an enzymatic assay of the Mn-bound enzyme was not conducted. Whether peptide deformylase functions with $\mathrm{Mn}^{2+}$ is unknown, but this enzyme is active with $\mathrm{Zn}^{2+}$ as a cofactor (Nguyen et al., 2007). Future work is needed to determine the metal specificity of BB0198 and the peptide deformylase and to identify $B b$ proteins that require $\mathrm{Mn}^{2+}$.

Surprisingly, some enhancement in the intracellular concentration of $\mathrm{Zn}^{2+}$ for $\triangle b m t A$ has been noted (Ouyang et al., 2009a; Wang et al., 2012). It has been hypothesized that within $\triangle b m t A$ there may be compensation for the reduction of $\mathrm{Mn}^{2+}$ by enhancing the transport of $\mathrm{Zn}^{2+}$ and thereby replacing the requirement of $\mathrm{Mn}^{2+}$ with $\mathrm{Zn}^{2+}$. Although future work is required to fully test this hypothesis, the replacement of $\mathrm{Mn}^{2+}$ for $\mathrm{Zn}^{2+}$ in $\mathrm{Mn}^{2+}$-dependent enzymes causes a pronounced reduction in catalytic efficiency or abrogates enzymatic activity altogether (Ose and Fridovich, 1976; Sobota and Imlay, 2011; Gu and Imlay, 2013). Metal-dependent transcription factors can utilize a variety of metals for function, i.e., $\mathrm{Mn}^{2+}$ or $\mathrm{Fe}^{2+}$ in the case of Fur (Privalle and Fridovich, 1993), and host metalsequestering proteins exhibit promiscuity in metal binding, which is demonstrated by the $\mathrm{Mn}^{2+}$ or $\mathrm{Zn}^{2+}$ binding site ( $\mathrm{S} 1$ site) in calprotectin (Damo et al., 2013). This is in contrast to metaldependent enzymes, which exhibit stringent metal specificity for activity, as is the case for SpoT/RelA homologs and Bb's SodA (Sy, 1977; Troxell et al., 2012; Aguirre et al., 2013). However, because many of $B b$ 's putative metalloenzymes are uncharacterized, the possibility exists that a significant number of these proteins can utilize either $\mathrm{Mn}^{2+}$ or $\mathrm{Zn}^{2+}$ within the cell.

\section{$B b^{\prime}$ 'S METAL REQUIREMENT WITHIN THE TICK}

The unfed tick is presumed to be a nutrient deprived environment for $B b$. Starvation conditions may mimic oxidative stress conditions and factors responsible for defense against ROS are also important for survival during starvation (Jenkins et al., 1988; Nystrom et al., 1996). $\mathrm{Bb}$ may require $\mathrm{Mn}^{2+}$ in order to defend against ROS that occurs during onset of the bloodmeal. Although $\mathrm{Mn}^{2+}$ complexed with other biological compounds, such as bicarbonate, are capable of degrading ROS, this requires large concentrations of intracellular $\mathrm{Mn}^{2+}$ that occurs within Lactobacillus plantarum (Archibald and Fridovich, 1981, 1982; Stadtman et al., 1990). In the only report to compare directly the intracellular $\mathrm{Mn}^{2+}$ content of $L$. plantarum with $B b$, it was observed that $B b$ contains 20 to 100 -fold lower intracellular $\mathrm{Mn}^{2+}$ compared to L. plantarum, indicating this is an unlikely mechanism for ROS defense within $B b$ (Posey and Gherardini, 2000). However, $B b$ 's intracellular $\mathrm{Mn}^{2+}$ can fluctuate during in vitro growth conditions (Troxell et al., 2013), suggesting that environmental conditions within the tick-mouse life cycle may exist whereby $B b$ could contain sufficient intracellular $\mathrm{Mn}^{2+}$ to degrade ROS in a manner similar to L. plantarum. Although sodA is required for infection of the murine host (Esteve-Gassent et al., 2009), the contribution of sodA within the tick vector is unknown. It is currently unclear if $B b$ contains a high intracellular $\mathrm{Mn}^{2+}$ within the unfed tick or is starved for metals. Because of the involvement of $\mathrm{BicA}$ in $\mathrm{Cu}^{2+}$ and $\mathrm{Zn}^{2+}$ homeostasis and since $\Delta b i c A$ exhibits a defect within the unfed tick (Li et al., 2007), the results support the notion that these two metals are limiting. In addition, the contribution of BmtA to the unfed tick is unknown.

\section{REGULATION OF $\sigma^{\mathrm{S}}$ BY $\mathrm{Zn}^{2+}$ AND $\mathrm{Mn}^{2+}$ WITHIN Bb}

$B b$ is capable of surviving within two diverse hosts through changes in gene expression, specifically outer surface lipoproteins that modulate adaptation within each host. Outer Surface Proteins A (OspA) and C (OspC) are a lipoproteins produced by $B b$ within the tick and animal host, respectively. $B b$ contains a limited genome that contains a relatively small number of transcription factors and sigma factors: $B b$ encodes only three sigma factors the housekeeping $\sigma^{70}$, and two alternative sigma 
factors, RpoN $\left(\sigma^{54}\right)$ and RpoS $\left(\sigma^{S}\right)$ (Fraser et al., 1997; Samuels, 2011; Radolf et al., 2012). In addition, $B b$ genome encodes only one bacterial enhancer binding protein (bEBP), known as Rrp2, which is involved in $\sigma^{54}$ activation. The requirement of the Rrp2RpoN-RpoS pathway (or Rrp $2-\sigma^{54}-\sigma^{S}$ sigma factor cascade) in the regulation of $\operatorname{sp} A$ and $\operatorname{sp} C$ demonstrates the importance of this regulatory network (Hubner et al., 2001; Yang et al., 2003; Caimano et al., 2004; Fisher et al., 2005; Gilbert et al., 2007). $\operatorname{Rrp} 2$ and $\sigma^{54}$ directly activates transcription of $r p o S$ (Smith et al., 2007; Blevins et al., 2009). $\sigma^{S}$ then activates transcription of $o s p C$ by direct binding to the promoter of ospC (Yang et al., 2005) and also represses expression of $\operatorname{spp} A$ (Caimano et al., 2007). In addition, BosR, a Fur/PerR-like family transcription factor and a $\mathrm{Zn}^{2+}$-dependent DNA binding protein, has been shown to be essential for transcription of rpoS (Ouyang et al., 2009b, 2011). More recently, Wang et al. demonstrated that BosR may also directly repress ospA (Wang et al., 2013). Because RpoS regulates many genes important for $B b$ transmission and mammalian infection such as $\operatorname{sp} C$, this pathway is essential for the enzootic cycle of $B b$ (Caimano et al., 2004; Grimm et al., 2004; Pal et al., 2004; Boardman et al., 2008; Ouyang et al., 2008). Moreover, bosR is required for transmission from the tick vector and infection of the mammalian host (Hyde et al., 2009; Ouyang et al., 2009b). Thus, $B b$ has evolved to utilize the transcription factor BosR for virulence.

$B b$ is a highly fastidious pathogen. The cultivation of $B b$ requires a complex medium that is analogous to cell culture media for eukaryotic cells (Barbour, 1984). Comparisons of $B b$ replication within a feeding tick and during in vitro growth at $35-37^{\circ} \mathrm{C}$ demonstrate that both conditions support growth with a generation time of $\approx 8-10 \mathrm{~h}$ (De Silva and Fikrig, 1995). Metal analysis of the cultivation medium for $B b$ indicates there is $\approx 5 \mu \mathrm{M} \mathrm{Zn}^{2+}, \approx 4 \mu \mathrm{M} \mathrm{Cu}^{2+}$, and $\approx 0.1 \mu \mathrm{M} \mathrm{Mn}^{2+}$ (Wang et al., 2012; Troxell et al., 2013). Besides $\mathrm{Fe}^{2+}$, other transition metals, such as $\mathrm{Zn}^{2+}$ and $\mathrm{Mn}^{2+}$ are known to influence gene regulation within bacterial pathogens (Corbin et al., 2008). Based on the $\mathrm{Zn}^{2+}$-dependent nature of BosR (Boylan et al., 2003; Katona et al., 2004), and because BosR regulates $r p o S, \mathrm{Zn}^{2+}$ could regulate $r p o S$ within $B b$.

Metal analysis indicates that while intracellular $\mathrm{Zn}^{2+}$ remained relatively constant under different conditions, $\mathrm{Mn}^{2+}$ was subject to temperature-dependent regulation within $\mathrm{Bb}$ (Troxell et al., 2013). Moreover, the intracellular $\mathrm{Mn}^{2+}$ can fluctuate 20 -fold during in vitro growth conditions and the temperaturedependent inverse concentration of intracellular of $\mathrm{Mn}^{2+}$ is reminiscent of the inverse regulation of $\operatorname{ssp} A$ and $\operatorname{ssp} C$ within $B b$ (Stevenson et al., 1995; Obonyo et al., 1999; Yang et al., 2000; Alverson et al., 2003). To test if $\mathrm{Mn}^{2+}$ could suppress regulation by $\sigma^{\mathrm{S}}, \mathrm{MnCl}_{2}$ was added to cultures growing under conditions of $\sigma^{\mathrm{S}}$ activation. The addition of $\mathrm{MnCl}_{2}$ increases intracellular $\mathrm{Mn}^{2+}$ and reduces the expression of $r p o S$ and $\sigma^{\mathrm{S}}$-activated ospC (Troxell et al., 2013). The addition of excess $\mathrm{ZnSO}_{4}$ increases the intracellular $\mathrm{Zn}^{2+}$, increases the level of BosR protein, and abrogates the repression of rpoS by $\mathrm{Mn}^{2+}$. Surprisingly, $\mathrm{MnCl}_{2}$ did

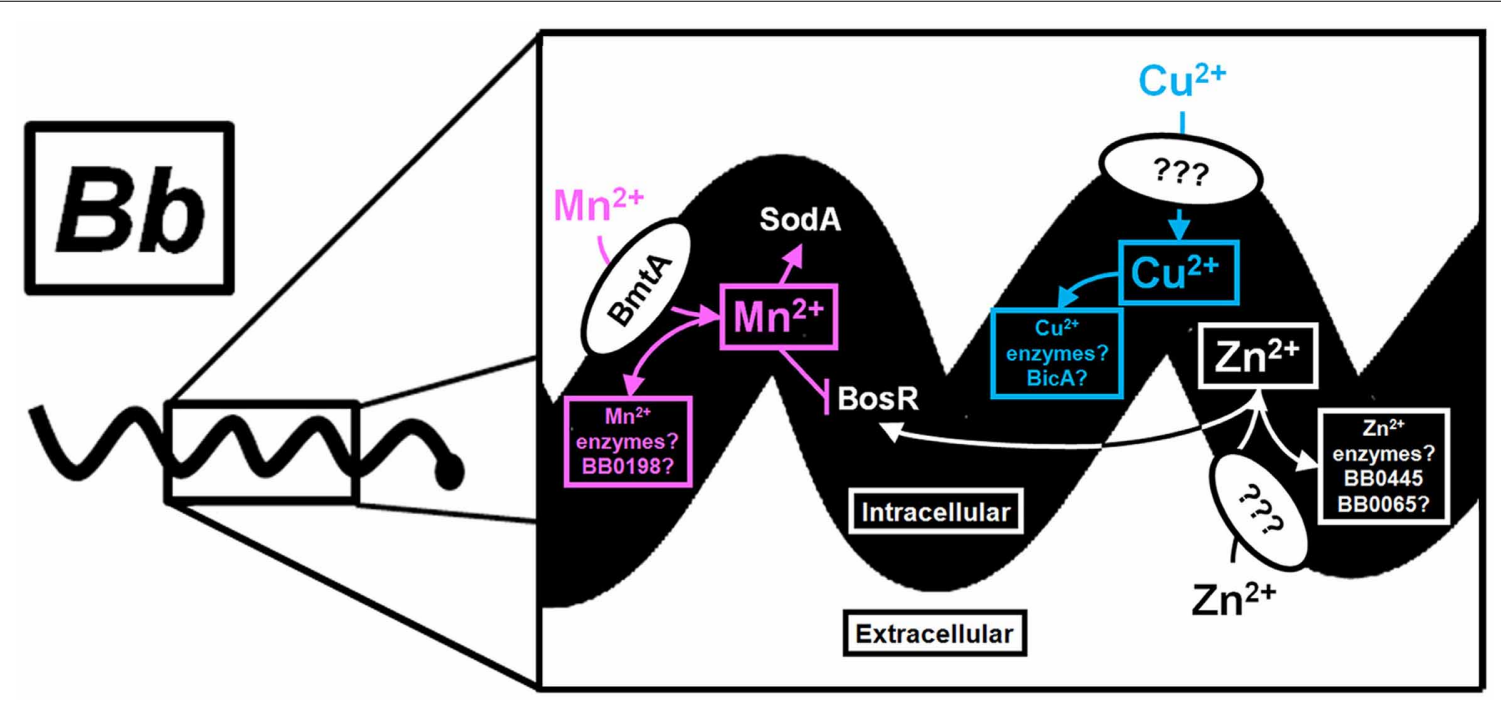

FIGURE 2 | Known and putative roles of $\mathrm{Mn}^{2+}, \mathrm{Cu}^{2+}$, and $\mathrm{Zn}^{2+}$ in gene regulation and metabolism of $\boldsymbol{B b}$. A schematic of the importance of transition metals within $B b$ is shown with a magnification of a section from a single $\mathrm{Bb}$ cell. Extracellular $\mathrm{Mn}^{2+}$ is transported through BmtA and supplies the appropriate cofactor for the Mn-SOD and possibly the SpoT/RelA homolog BB0198 (designated by a pink arrow). In addition, $\mathrm{Mn}^{2+}$ reduces the level of BosR protein (designated by a pink blunted line), which controls transcription of the alternative sigma factor, rpoS (not shown). The putative role of $\mathrm{Mn}^{2+}$ as a cofactor for additional unknown enzymes is shown with a pink box. $\mathrm{Zn}^{2+}$ transport is uncharacterized in $B b$, but is presumed to be transported by a membrane bound protein. The requirement for $\mathrm{Zn}^{2+}$ within
$B b$ is likely to include enzymes within glycolysis, such as fructose 1,6-bisphosphatase (BB0445), and the peptide deformylase (BB0065) shown in the white box. $\mathrm{Zn}^{2+}$ is a known cofactor for the DNA binding protein BosR. Therefore, the intracellular $\mathrm{Mn}^{2+}: \mathrm{Zn}^{2+}$ can modulate the level of BosR protein. The transporter for $\mathrm{Cu}^{2+}$ and the role of $\mathrm{Cu}^{2+}$ within $\mathrm{Bb}$ is unknown, but BicA may be involved in transport and homeostasis (blue box). Moreover, the contribution of $\mathrm{Cu}^{2+}$ to gene regulation within $B b$ is unknown, but is predicted to involve redox sensing transcription factors (Changela et al., 2003; Gomez-Santos et al., 2011). Future work is required to elucidate the complete role of these metals in gene regulation and physiology of this important vector borne pathogen. 
not influence transcription of bosR, but reduced the level of the BosR protein (Troxell et al., 2013). In addition, deletion of $b m t A$ in two infectious strains does not alter bos $R$ transcription, but enhances temperature-dependent activation in the level of BosR, which results in increased transcription of $r p o S$ and $o s p C$. As an earlier study shows, the BosR protein level is increased by $\mathrm{CO}_{2}$ despite the inability of dissolved $\mathrm{CO}_{2}$ to regulate transcription of bosR (Hyde et al., 2007). These combined results suggest that either metals or $\mathrm{CO}_{2}$ may control the level of the BosR protein, which activates transcription of rpoS. Correlation of the intracellular $\mathrm{Mn}^{2+}: \mathrm{Zn}^{2+}$ indicates that the ratio between these two metals play an important role in the level of BosR protein and rpoS regulation. Collectively, these results support the hypothesis that a combined reduction in intracellular $\mathrm{Mn}^{2+}$ while increasing $\mathrm{Zn}^{2+}$ regulates $\sigma^{\mathrm{S}}$ by dramatically enhancing the level of BosR protein.

Why does $B b$ require $b m t A$ for the enzootic cycle? The presence of excess $\mathrm{Mn}^{2+}$ suggests there is a collection of unknown targets that require $\mathrm{Mn}^{2+}$ for activity. One function may be to control $\sigma^{S}$ activation during the enzootic cycle. Precise regulation of $\operatorname{ssp} C$ and other outer surface proteins, such as $v l s E$, is required for infection of the murine host; constitutive activation of either surface protein results in rapid elimination of $B b$ by either innate cells or the humoral response of the host (Liang et al., 2002; Xu et al., 2006, 2008a,b). In the absence of any defined metabolic requirement for $\mathrm{Mn}^{2+}$ within $\mathrm{Bb}$, the importance of $\mathrm{Mn}^{2+}$ to the enzootic cycle could be to control regulation of highly immunogenic outer surface proteins. Nevertheless, the limited genome of $\mathrm{Bb}$ encodes several homologs that may require $\mathrm{Mn}^{2+}$ for activity. Furthermore, BmtA appears to influence not only the intracellular $\mathrm{Mn}^{2+}$ concentration, but also the concentrations of $\mathrm{Cu}^{2+}$ and $\mathrm{Zn}^{2+}$. How $\mathrm{Zn}^{2+}$ and $\mathrm{Cu}^{2+}$ are transported within $\mathrm{Bb}$ is unknown, but it is likely that these metals are required for proper regulation of virulence genes and unknown metabolic genes. Future work will no doubt shed light on the importance of these metals as cofactors and their influence on gene regulation. This is summarized in Figure 2, which depicts the known and putative roles of $\mathrm{Mn}^{2+}, \mathrm{Cu}^{2+}$, and $\mathrm{Zn}^{2+}$ within $\mathrm{Bb}$.

\section{CONCLUSIONS}

Unlike most bacterial pathogens, $B b$ does not require $\mathrm{Fe}^{2+}$ for growth, which presents a unique model system to study metaldependent gene regulation and stress responses. The bloodmeal is rich in $\mathrm{Zn}^{2+} / \mathrm{Cu}^{2+}$ and relatively poor in $\mathrm{Mn}^{2+}$, which suggests that $B b$ 's intracellular $\mathrm{Zn}^{2+} / \mathrm{Cu}^{2+}$ content may increase through unidentified transporters (Figure 2). Because $\mathrm{Mn}^{2+}$ regulates the BosR protein level, but not bosR transcription (Troxell et al., 2013), the low $\mathrm{Mn}^{2+}$ content in blood may further enhance expression $r p o S$, which is required for $B b$ to exit the tick midgut and reach the salivary glands during tick feeding (Fisher et al., 2005; Dunham-Ems et al., 2012). How does $B b$ coordinate the regulation of transport of $\mathrm{Mn}^{2+}, \mathrm{Cu}^{2+}$, and $\mathrm{Zn}^{2+}$ during the enzootic cycle? What is apparent from in vitro work is that the intracellular $\mathrm{Mn}^{2+}: \mathrm{Zn}^{2+}$ ratio regulates transcription of the alternative sigma factor, $r p o S$, which controls activation of genes required for infection of mammals. A caveat to these studies is the heavy reliance on in vitro experiments due to the difficulties of measuring intracellular metal content while detecting changes in gene expression during in vivo studies. Infection studies with $\Delta b i c A$ and $\Delta b m t A$ demonstrate the importance of these genes within the enzootic cycle, but the mechanism for why $B b$ requires them is unknown. Although the contribution to the unfed tick is known for $b i c A$, the contribution of $b m t A$ to survival within the dormant tick is unknown. How BicA and BmtA control metal homeostasis or gene expression in vivo would greatly improve our understanding of their importance in infection. Moreover, the identification of a dedicated $\mathrm{Zn}$ transport system and $\mathrm{Cu}$ transport system within $B b$ would provide additional and much needed clarity. It is clear that we are only beginning to understand the importance of metals in the metabolism and gene regulation within the Lyme disease spirochete

\section{ACKNOWLEDGMENTS}

Bryan Troxell was supported by NIH T32 AI060519. Funding for this work was partially provided by NIH grants AI083640 and AI085242, Indiana INGEN and METACyt grants of Indiana University, funded by the Lilly Endowment, Inc (to X. Frank Yang).

\section{REFERENCES}

Aguirre, J. D., Clark, H. M., McIlvin, M., Vazquez, C., Palmere, S. L., Grab, D. J., et al. (2013). A manganese-rich environment supports superoxide dismutase activity in a Lyme disease pathogen, Borrelia burgdorferi. J. Biol. Chem. 288, 8468-8478. doi: 10.1074/jbc.M112.433540

Alverson, J., Bundle, S. F., Sohaskey, C. D., Lybecker, M. C., and Samuels, D. S. (2003). Transcriptional regulation of the ospAB and ospC promoters from Borrelia burgdorferi. Mol. Microbiol. 48, 1665-1677. doi: 10.1046/j.13652958.2003.03537.x

Anjem, A., Varghese, S., and Imlay, J. A. (2009). Manganese import is a key element of the OxyR response to hydrogen peroxide in Escherichia coli. Mol. Microbiol. 72, 844-858. doi: 10.1111/j.1365-2958.2009.06699.x

Archibald, F. S., and Fridovich, I. (1981). Manganese and defenses against oxygen toxicity in Lactobacillus plantarum. J. Bacteriol. 145, 442-451.

Archibald, F. S., and Fridovich, I. (1982). The scavenging of superoxide radical by manganous complexes: in vitro. Arch. Biochem. Biophys. 214, 452-463. doi: 10.1016/0003-9861(82)90049-2

Barbour, A. G. (1984). Isolation and cultivation of Lyme disease spirochetes. Yale J. Biol. Med. 57, 521-525.

Blevins, J. S., Xu, H., He, M., Norgard, M. V., Reitzer, L., and Yang, X. F. (2009). Rrp2, a sigma54-dependent transcriptional activator of Borrelia burgdorferi, activates rpoS in an enhancer-independent manner. J. Bacteriol. 191, 2902-2905. doi: 10.1128/JB.01721-08

Boardman, B. K., He, M., Ouyang, Z., Xu, H., Pang, X., and Yang, X. F. (2008). Essential role of the response regulator Rrp2 in the infectious cycle of Borrelia burgdorferi. Infect. Immun. 76, 3844-3853. doi: 10.1128/IAI. 00467-08

Bourret, T. J., Boylan, J. A., Lawrence, K. A., and Gherardini, F. C. (2011). Nitrosative damage to free and zinc-bound cysteine thiols underlies nitric oxide toxicity in wild-type Borrelia burgdorferi. Mol. Microbiol. 81, 259-273. doi: 10.1111/j.1365-2958.2011.07691.x

Boylan, J. A., Posey, J. E., and Gherardini, F. C. (2003). Borrelia oxidative stress response regulator, BosR: a distinctive $\mathrm{Zn}$-dependent transcriptional activator. Proc. Natl. Acad. Sci. U.S.A. 100, 11684-11689. doi: 10.1073/pnas.2032956100

Bugrysheva, J. V., Bryksin, A. V., Godfrey, H. P., and Cabello, F. C. (2005). Borrelia burgdorferi rel is responsible for generation of guanosine- $3^{\prime}$-diphosphate$5^{\prime}$-triphosphate and growth control. Infect. Immun. 73, 4972-4981. doi: 10.1128/IAI.73.8.4972-4981.2005

Caimano, M. J., Eggers, C. H., Hazlett, K. R., and Radolf, J. D. (2004). RpoS is not central to the general stress response in Borrelia burgdorferi but does control expression of one or more essential virulence determinants. Infect. Immun. 72, 6433-6445. doi: 10.1128/IAI.72.11.6433-6445.2004 
Caimano, M. J., Iyer, R., Eggers, C. H., Gonzalez, C., Morton, E. A., and Gilbert, M. A., et al. (2007). Analysis of the RpoS regulon in Borrelia burgdorferi in response to mammalian host signals provides insight into RpoS function during the enzootic cycle. Mol. Microbiol. 65, 1193-1217. doi: 10.1111/j.1365-2958. 2007.05860.x

Changela, A., Chen, K., Xue, Y., Holschen, J., Outten, C. E., O’Halloran, T. V., et al. (2003). Molecular basis of metal-ion selectivity and zeptomolar sensitivity by CueR. Science 301, 1383-1387. doi: 10.1126/science.1085950

Concepcion, M. B., and Nelson, D. R. (2003). Expression of spoT in Borrelia burgdorferi during serum starvation. J. Bacteriol. 185, 444-452. doi: 10.1128/JB.185.2.444-452.2003

Corbin, B. D., Seeley, E. H., Raab, A., Feldmann, J., Miller, M. R., Torres, V. J., et al. (2008). Metal chelation and inhibition of bacterial growth in tissue abscesses. Science 319, 962-965. doi: 10.1126/science.1152449

Damo, S. M., Kehl-Fie, T. E., Sugitani, N., Holt, M. E., Rathi, S., Murphy, W. J., et al. (2013). Molecular basis for manganese sequestration by calprotectin and roles in the innate immune response to invading bacterial pathogens. Proc. Natl. Acad. Sci. U.S.A. 110, 3841-3846. doi: 10.1073/pnas.1220341110

De Silva, A. M., and Fikrig, E. (1995). Growth and migration of Borrelia burgdorferi in Ixodes ticks during blood feeding. Am. J. Trop. Med. Hyg. 53, 397-404.

Dunham-Ems, S. M., Caimano, M. J., Eggers, C. H., and Radolf, J. D. (2012). Borrelia burgdorferi requires the alternative sigma factor RpoS for dissemination within the vector during tick-to-mammal transmission. PLoS Pathog. 8:e1002532. doi: 10.1371/journal.ppat.1002532

Esteve-Gassent, M. D., Elliott, N. L., and Seshu, J. (2009). sodA is essential for virulence of Borrelia burgdorferi in the murine model of Lyme disease. Mol. Microbiol. 71, 594-612. doi: 10.1111/j.1365-2958.2008.06549.x

Esteves, E., Fogaca, A. C., Maldonado, R., Silva, F. D., Manso, P. P., Pelajo-Machado, M., et al. (2009). Antimicrobial activity in the tick Rhipicephalus (Boophilus) microplus eggs: cellular localization and temporal expression of microplusin during oogenesis and embryogenesis. Dev. Comp. Immunol. 33, 913-919. doi: 10.1016/j.dci.2009.02.009

Fisher, M. A., Grimm, D., Henion, A. K., Elias, A. F., Stewart, P. E., Rosa, P. A., et al. (2005). Borrelia burgdorferi sigma54 is required for mammalian infection and vector transmission but not for tick colonization. Proc. Natl. Acad. Sci. U.S.A. 102, 5162-5167. doi: 10.1073/pnas.0408536102

Fraser, C. M., Casjens, S., Huang, W. M., Sutton, G. G., Clayton, R., Lathigra, R., et al. (1997). Genomic sequence of a Lyme disease spirochaete, Borrelia burgdorferi. Nature 390, 580-586. doi: 10.1038/37551

Gilbert, M. A., Morton, E. A., Bundle, S. F., and Samuels, D. S. (2007). Artificial regulation of $\operatorname{sp} \mathrm{C}$ expression in Borrelia burgdorferi. Mol. Microbiol. 63, 1259-1273. doi: 10.1111/j.1365-2958.2007.05593.x

Gomez-Santos, N., Perez, J., Sanchez-Sutil, M. C., Moraleda-Munoz, A., and Munoz-Dorado, J. (2011). CorE from Myxococcus xanthus is a copperdependent RNA polymerase sigma factor. PLoS Genet. 7:e1002106. doi: 10.1371/journal.pgen.1002106

Grimm, D., Tilly, K., Byram, R., Stewart, P. E., Krum, J. G., Bueschel, D. M., et al. (2004). Outer-surface protein $\mathrm{C}$ of the Lyme disease spirochete: a protein induced in ticks for infection of mammals. Proc. Natl. Acad. Sci. U.S.A. 101, 3142-3147. doi: 10.1073/pnas.0306845101

Gu, M., and Imlay, J. A. (2013). Superoxide poisons mononuclear iron enzymes by causing mismetallation. Mol. Microbiol. 89, 123-134. doi: 10.1111/mmi.12263

Guerinot, M. L. (2000). The ZIP family of metal transporters. Biochim. Biophys. Acta 1465, 190-198. doi: 10.1016/S0005-2736(00)00138-3

Hubner, A., Yang, X., Nolen, D. M., Popova, T. G., Cabello, F. C., and Norgard, M. V. (2001). Expression of Borrelia burgdorferi OspC and DbpA is controlled by a RpoN-RpoS regulatory pathway. Proc. Natl. Acad. Sci. U.S.A. 98, 12724-12729. doi: 10.1073/pnas.231442498

Hyde, J. A., Shaw, D. K., Smith Iii, R., Trzeciakowski, J. P., and Skare, J. T. (2009). The BosR regulatory protein of Borrelia burgdorferi interfaces with the RpoS regulatory pathway and modulates both the oxidative stress response and pathogenic properties of the Lyme disease spirochete. Mol. Microbiol. 74, 1344-1355. doi: 10.1111/j.1365-2958.2009.06951.x

Hyde, J. A., Trzeciakowski, J. P., and Skare, J. T. (2007). Borrelia burgdorferi alters its gene expression and antigenic profile in response to $\mathrm{CO} 2$ levels. J. Bacteriol. 189, 437-445. doi: 10.1128/JB.01109-06

Jain, R., Chen, D., White, R. J., Patel, D. V., and Yuan, Z. (2005). Bacterial Peptide deformylase inhibitors: a new class of antibacterial agents. Curr. Med. Chem. 12, 1607-1621. doi: 10.2174/0929867054367194
Jenkins, D. E., Schultz, J. E., and Matin, A. (1988). Starvation-induced cross protection against heat or $\mathrm{H} 2 \mathrm{O} 2$ challenge in Escherichia coli. J. Bacteriol. 170, 3910-3914.

Katona, L. I., Tokarz, R., Kuhlow, C. J., Benach, J., and Benach, J. L. (2004). The fur homologue in Borrelia burgdorferi. J. Bacteriol. 186, 6443-6456. doi: 10.1128/JB.186.19.6443-6456.2004

Kehl-Fie, T. E., Chitayat, S., Hood, M. I., Damo, S., Restrepo, N., Garcia, C., et al. (2011). Nutrient metal sequestration by calprotectin inhibits bacterial superoxide defense, enhancing neutrophil killing of Staphylococcus aureus. Cell Host Microbe 10, 158-164. doi: 10.1016/j.chom.2011.07.004

Kehl-Fie, T. E., and Skaar, E. P. (2010). Nutritional immunity beyond iron: a role for manganese and zinc. Curr. Opin. Chem. Biol. 14, 218-224. doi: 10.1016/j.cbpa.2009.11.008

Li, X., Pal, U., Ramamoorthi, N., Liu, X., Desrosiers, D. C., Eggers, C. H., et al. (2007). The Lyme disease agent Borrelia burgdorferi requires BB0690, a Dps homologue, to persist within ticks. Mol. Microbiol. 63, 694-710. doi: 10.1111/j.1365-2958.2006.05550.x

Liang, F. T., Jacobs, M. B., Bowers, L. C., and Philipp, M. T. (2002). An immune evasion mechanism for spirochetal persistence in Lyme borreliosis. J. Exp. Med. 195, 415-422. doi: 10.1084/jem.20011870

Liu, J. Z., Jellbauer, S., Poe, A. J., Ton, V., Pesciaroli, M., Kehl-Fie, T. E., et al. (2012). Zinc sequestration by the neutrophil protein calprotectin enhances Salmonella growth in the inflamed gut. Cell Host Microbe 11, 227-239. doi: 10.1016/j.chom.2012.01.017

Lusitani, D., Malawista, S. E., and Montgomery, R. R. (2003). Calprotectin, an abundant cytosolic protein from human polymorphonuclear leukocytes, inhibits the growth of Borrelia burgdorferi. Infect. Immun. 71, 4711-4716. doi: 10.1128/IAI.71.8.4711-4716.2003

Magnusson, L. U., Farewell, A., and Nystrom, T. (2005). ppGpp: a global regulator in Escherichia coli. Trends Microbiol. 13, 236-242. doi: 10.1016/j.tim.2005. 03.008

Nguyen, K. T., Wu, J. C., Boylan, J. A., Gherardini, F. C., and Pei, D. (2007). Zinc is the metal cofactor of Borrelia burgdorferi peptide deformylase. Arch. Biochem. Biophys. 468, 217-225. doi: 10.1016/j.abb.2007.09.023

Nystrom, T., Larsson, C., and Gustafsson, L. (1996). Bacterial defense against aging: role of the Escherichia coli ArcA regulator in gene expression, readjusted energy flux and survival during stasis. EMBO J. 15, 3219-3228.

Obonyo, M., Munderloh, U. G., Fingerle, V., Wilske, B., and Kurtti, T. J. (1999). Borrelia burgdorferi in tick cell culture modulates expression of outer surface proteins A and C in response to temperature. J. Clin. Microbiol. 37, 2137-2141.

Ojaimi, C., Brooks, C., Casjens, S., Rosa, P., Elias, A., Barbour, A., et al. (2003). Profiling of temperature-induced changes in Borrelia burgdorferi gene expression by using whole genome arrays. Infect. Immun. 71, 1689-1705. doi: 10.1128/IAI.71.4.1689-1705.2003

Ose, D. E., and Fridovich, I. (1976). Superoxide dismutase. Reversible removal of manganese and its substitution by cobalt, nickel or zinc. J. Biol. Chem. 251, 1217-1218.

Ouyang, Z., Blevins, J. S., and Norgard, M. V. (2008). Transcriptional interplay among the regulators Rrp2, RpoN, and RpoS in Borrelia burgdorferi. Microbiology 154, 2641-2658. doi: 10.1099/mic.0.2008/019992-0

Ouyang, Z., Deka, R. K., and Norgard, M. V. (2011). BosR (BB0647) controls the RpoN-RpoS regulatory pathway and virulence expression in Borrelia burgdorferi by a novel DNA-binding mechanism. PLoS. Pathog 7, e1001272. doi: 10.1371/ journal.ppat.1001272

Ouyang, Z., He, M., Oman, T., Yang, X. F., and Norgard, M. V. (2009a). A manganese transporter, BB0219 (BmtA), is required for virulence by the Lyme disease spirochete, Borrelia burgdorferi. Proc. Natl. Acad. Sci. U.S.A. 106, 3449-3454. doi: 10.1073/pnas.0812999106

Ouyang, Z., Kumar, M., Kariu, T., Haq, S., Goldberg, M., Pal, U., et al. (2009b). BosR (BB0647) governs virulence expression in Borrelia burgdorferi. Mol. Microbiol. 74, 1331-1343. doi: 10.1111/j.1365-2958.2009.06945.x

Pal, U., Yang, X., Chen, M., Bockenstedt, L. K., Anderson, J. F., Flavell, R. A., et al. (2004). OspC facilitates Borrelia burgdorferi invasion of Ixodes scapularis salivary glands. J. Clin. Invest. 113, 220-230. doi: 10.1172/JCI19894

Posey, J. E., and Gherardini, F. C. (2000). Lack of a role for iron in the Lyme disease pathogen. Science 288, 1651-1653. doi: 10.1126/science.288.5471.1651

Privalle, C. T., and Fridovich, I. (1993). Iron specificity of the Fur-dependent regulation of the biosynthesis of the manganese-containing superoxide dismutase in Escherichia coli. J. Biol. Chem. 268, 5178-5181. 
Radolf, J. D., Caimano, M. J., Stevenson, B., and Hu, L. T. (2012). Of ticks, mice and men: understanding the dual-host lifestyle of Lyme disease spirochaetes. Nat. Rev. Microbiol. 10, 87-99. doi: 10.1038/nrmicro2714

Radolf, J. D., and Samuels, D. S. (eds.). (2010). Borrelia: Molecular Biology, Host Interaction, and Pathogenesis. Norfolk: Caister Academic Press.

Samuels, D. S. (2011). Gene regulation in Borrelia burgdorferi. Annu. Rev. Microbiol. 65, 479-499. doi: 10.1146/annurev.micro.112408.134040

Silva, F. D., Rezende, C. A., Rossi, D. C., Esteves, E., Dyszy, F. H., Schreier, S., et al. (2009). Structure and mode of action of microplusin, a copper II-chelating antimicrobial peptide from the cattle tick Rhipicephalus (Boophilus) microplus. J. Biol. Chem. 284, 34735-34746. doi: 10.1074/jbc.M109.016410

Silva, F. D., Rossi, D. C., Martinez, L. R., Frases, S., Fonseca, F. L., Campos, C. B., et al. (2011). Effects of microplusin, a copper-chelating antimicrobial peptide, against Cryptococcus neoformans. FEMS Microbiol. Lett. 324, 64-72. doi: 10.1111/j.1574-6968.2011.02386.x

Smith, A. H., Blevins, J. S., Bachlani, G. N., Yang, X. F., and Norgard, M. V. (2007). Evidence that RpoS (sigmaS) in Borrelia burgdorferi is controlled directly by RpoN (sigma54/sigmaN). J. Bacteriol. 189, 2139-2144. doi: 10.1128/JB. 01653-06

Sobota, J. M., and Imlay, J. A. (2011). Iron enzyme ribulose-5-phosphate 3epimerase in Escherichia coli is rapidly damaged by hydrogen peroxide but can be protected by manganese. Proc. Natl. Acad. Sci. U.S.A. 108, 5402-5407. doi: 10.1073/pnas.1100410108

Srinivasan, V. B., Vaidyanathan, V., Mondal, A., Venkataramaiah, M., and Rajamohan, G. (2012). Functional characterization of a novel $\mathrm{Mn} 2+$ dependent protein serine/threonine kinase KpnK, produced by Klebsiella pneumoniae strain MGH78578. FEBS Lett. 586, 3778-3786. doi: 10.1016/j.febslet.2012.09.007

Stadtman, E. R., Berlett, B. S., and Chock, P. B. (1990). Manganese-dependent disproportionation of hydrogen peroxide in bicarbonate buffer. Proc. Natl. Acad. Sci. U.S.A. 87, 384-388. doi: 10.1073/pnas.87.1.384

Stevenson, B., Schwan, T. G., and Rosa, P. A. (1995). Temperature-related differential expression of antigens in the Lyme disease spirochete, Borrelia burgdorferi. Infect. Immun. 63, 4535-4539.

Sun, D., Lee, G., Lee, J. H., Kim, H. Y., Rhee, H. W., Park, S. Y., et al. (2010). A metazoan ortholog of SpoT hydrolyzes ppGpp and functions in starvation responses. Nat. Struct. Mol. Biol. 17, 1188-1194. doi: 10.1038/nsmb.1906

Sy, J. (1977). In vitro degradation of guanosine $5^{\prime}$-diphosphate, $3^{\prime}$-diphosphate. Proc. Natl. Acad. Sci. U.S.A. 74, 5529-5533. doi: 10.1073/pnas.74.12.5529

Troxell, B., Xu, H., and Yang, X. F. (2012). Borrelia burgdorferi, a pathogen that lacks iron, encodes manganese-dependent superoxide dismutase essential for resistance to streptonigrin. J. Biol. Chem. 287, 19284-19293. doi: 10.1074/jbc.M112.344903

Troxell, B., Ye, M., Yang, Y., Carrasco, S. E., Lou, Y., and Yang, X. F. (2013). Manganese and zinc regulate virulence determinants in Borrelia burgdorferi. Infect. Immun. 81, 2743-2752. doi: 10.1128/IAI.00507-13

Wang, P., Dadhwal, P., Cheng, Z., Zianni, M. R., Rikihisa, Y., Liang, F. T., et al. (2013). Borrelia burgdorferi oxidative stress regulator BosR directly represses lipoproteins primarily expressed in the tick during mammalian infection. $\mathrm{Mol}$. Microbiol. 89, 1140-1153. doi: 10.1111/mmi.12337

Wang, P., Lutton, A., Olesik, J., Vali, H., and Li, X. (2012). A novel iron- and copperbinding protein in the Lyme disease spirochaete. Mol. Microbiol. 86, 1441-1451. doi: $10.1111 / \mathrm{mmi} .12068$

Xu, Q., McShan, K., and Liang, F. T. (2008a). Essential protective role attributed to the surface lipoproteins of Borrelia burgdorferi against innate defences. Mol. Microbiol. 69, 15-29. doi: 10.1111/j.1365-2958.2008.06264.x

Xu, Q., McShan, K., and Liang, F. T. (2008b). Modification of Borrelia burgdorferi to overproduce OspA or VlsE alters its infectious behaviour. Microbiology 154, 3420-3429. doi: 10.1099/mic.0.2008/019737-0

Xu, Q., Seemanapalli, S. V., McShan, K., and Liang, F. T. (2006). Constitutive expression of outer surface protein $\mathrm{C}$ diminishes the ability of Borrelia burgdorferi to evade specific humoral immunity. Infect. Immun. 74, 5177-5184. doi: 10.1128/IAI.00713-06

Yang, X., Goldberg, M. S., Popova, T. G., Schoeler, G. B., Wikel, S. K., Hagman, K. E., et al. (2000). Interdependence of environmental factors influencing reciprocal patterns of gene expression in virulent Borrelia burgdorferi. Mol. Microbiol. 37, 1470-1479. doi: 10.1046/j.1365-2958.2000.02104.x

Yang, X. F., Alani, S. M., and Norgard, M. V. (2003). The response regulator Rrp2 is essential for the expression of major membrane lipoproteins in Borrelia burgdorferi. Proc. Natl. Acad. Sci. U.S.A. 100, 11001-11006. doi: 10.1073/pnas.1834315100

Yang, X. F., Lybecker, M. C., Pal, U., Alani, S. M., Blevins, J., Revel, A. T., et al. (2005). Analysis of the ospC regulatory element controlled by the RpoN-RpoS regulatory pathway in Borrelia burgdorferi. J. Bacteriol. 187, 4822-4829. doi: 10.1128/JB.187.14.4822-4829.2005

Yui, S., Nakatani, Y., and Mikami, M. (2003). Calprotectin (S100A8/S100A9), an inflammatory protein complex from neutrophils with a broad apoptosisinducing activity. Biol. Pharm. Bull. 26, 753-760. doi: 10.1248/bpb.26.753

Conflict of Interest Statement: The authors declare that the research was conducted in the absence of any commercial or financial relationships that could be construed as a potential conflict of interest.

Received: 30 July 2013; accepted: 29 October 2013; published online: 15 November 2013.

Citation: Troxell B and Yang XF (2013) Metal-dependent gene regulation in the causative agent of Lyme disease. Front. Cell. Infect. Microbiol. 3:79. doi: 10.3389/ fcimb.2013.00079

This article was submitted to the journal Frontiers in Cellular and Infection Microbiology.

Copyright (c) 2013 Troxell and Yang. This is an open-access article distributed under the terms of the Creative Commons Attribution License (CC BY). The use, distribution or reproduction in other forums is permitted, provided the original author(s) or licensor are credited and that the original publication in this journal is cited, in accordance with accepted academic practice. No use, distribution or reproduction is permitted which does not comply with these terms. 